\title{
Atualização do Protocolo Operacional Padrão da Saúde Bucal, do mu- nicípio de Atílio Vivácqua do Espirito Santo, Brasil.
}

\author{
Luciana Maria Gonçalves Furtado Ramos ${ }^{1}$ \\ Lorrayne Coque Fonseca \\ Natiany de Lima Torres ${ }^{1}$ \\ Margareth Machado ${ }^{1}$
}

\section{$\underline{\text { RESUMO }}$}

Os profissionais da odontologia se enquadram em grupos de grande exposição ao COVID-19, considerando que o ambiente odontológico favorece a infecção cruzada permitindo um maior índice de contágio viral devido a uma comunicação face a face, exposição a aerossóis compostos de saliva, sangue e outros fluidos. Protocolos rigorosos e eficientes são necessários para o controle da transmissão. Para tanto, os profissionais da odontologia necessitam conhecer sobre as medidas de prevenção e controle do COVID-19.0bjetivo: O trabalho tem por objetivo orientar sobre as medidas a serem adotadas pelos profissionais de odontologia de Atílio Vivácqua, atualizadas com base nas evidências científicas mais recentes, a fim de reduzir os riscos de transmissão do vírus SARS-CoV-2. Metodologia: A metodologia usada foi revisão integrativa da literatura com busca recente na base de dados com indexação de artigos nacionais de revistas, websites e Portarias do Ministério da saúde do Brasil. Conclusão: $O$ estabelecimento de protocolos facilita o entendimento da equipe e a percepção de saúde.

\section{INTRODUÇÃO}

A preocupação com a Biossegurança está cada vez mais presente no cotidiano da Odontologia, devido à importância para preservação da saúde do paciente, profissional e equipe auxiliar. O surgimento de algumas patologias infectocontagiosas é relatado desde os tempos remotos, que causavam infecções e proliferação de microrganismos no meio ambiente. Alguns relatos da existência desses microrganismos e técnicas utilizadas para controle são citados desde a época dos povos na antiguidade na tentativa de diminuir ou eliminar esses agentes patógenos, que poderiam propagar ou disseminar infecções entre os povos ${ }^{[1]}$.

No ano de 2019 surgiu uma nova cepa do Coronavírus, no qual foi nomeado como SARS-CoV-2. A doença respiratória aguda causada pelo SARS-CoV-2 foi detectada pela primeira vez na cidade de Wuhan na China, a partir do aumento do número de casos de pneumonia grave e de etiologia desconhecida, seguida por ampla disseminação e crescimento expressivo do número de casos no mundo todo [2-6]

Durante a pandemia, os cirurgiões-dentistas foram classificados como categoria de alto risco devido ao potencial de exposição ao coronavírus através de procedimentos que geram aerossol. O ambiente odontológico parece, de fato, oferecer alto risco de contágio pela exposição à saliva, sangue e aerossol/ gotículas. A transmissão de SARS-CoV-2 durante procedimentos odontológicos pode, portanto, ocorrer pela inalação de aerossóis/gotículas de indivíduos infectados ou pelo contato direto com membranas mucosas, fluidos orais ou instrumentos e superfícies contaminadas ${ }^{[7-9]}$.

\footnotetext{
Instituto Capixaba de Ensino, Pesquisa e Inovação em Saúde, Secretaria Estadual de Saúde do Espírito Santo Rua Eng. Guilherme José Monjardim Varejão, 255, Edifício Enseada Plaza, $3^{\circ}$ Andar - Enseada do Suá, 29050-260, Vitória, ES, Brasil. Correspondência para: Machado M. E-mail: <margo_machado@yahoo.com.br>

Como citar este artigo
} 
Diante da situação atual em que o mundo vive, os cirurgiões-dentistas, ciente de sua responsabilidade e dos riscos inerentes de sua profissão, devem ter conhecimento das medidas e recomendações no atendimento aos pacientes. Essas medidas de proteção objetivam evitar ou reduzir procedimentos que produzam gotículas ou aerossóis e inclui a preparação da equipe de saúde bucal, ajustes nos equipamentos de proteção individual (EPIs) e recomendações para limpeza e desinfecção das superfícies [10,11].

Considerando a severidade da pandemia de COVID-19 e as mais recentes recomendações dos órgãos e autoridades em saúde, este estudo foi elaborado com o intuito de aprimorar o procedimento operacional padrão da saude bucal (POP), enfatizando os cuidados necessários para a proteção dos profissionais e pacientes de forma mais segura ${ }^{[12]}$.

\section{OBJETIVOS}

- Aprimoramento do protocolo de biossegurança na atenção básica já existente no município de Atílio Vivácqua, durante a pandemia da COVID-19.

- Orientar e atualizar os profissionais de odontologia do município de Atílio Vivácqua sobre as medidas a serem adotadas frente à pandemia do COVID-19.

\section{MÉTODOS}

Uma análise criteriosa da literatura, portarias e normas técnicas do Ministério da Saúde, Secretarias Estaduais e Municipais e de Entidades de Classe foi realizada no período de novembro de 2020 à março de 2021 e os dados obtidos foram discutidos em reuniões a partir das quais elaborou-se um novo documento modificando/complementando 0 que estabelecia previamente o Procedimento Operacional Padrão da Saude Bucal (POP) do município de Atílio Vivácqua, do estado do Espirito Santo, Brasil.O POP é uma forma de sistematizar as tarefas diárias dos cirurgiões dentistas e seus auxiliares ${ }^{[2-6]}$.

OnovoPOPcontêm orientações e recomendações acerca de como se deve organizar a limpeza dos instrumentais e materiais, acondicionamento dos artigos para esterilização em autoclave, o carregamento da autoclave, esterilização em autoclave, armazenamento dos artigos esterilizados, testes biológicos da autoclave, higienização antisséptica das mãos (alcóolica) ou lavagem simples das mãos, limpeza e desinfecção das peças de mão, limpeza e desinfecção do sistema de sucção, aplicação e troca das barreiras plásticas descartáveis, limpeza dos ambientes, disposição e gerenciamento dos resíduos de serviços de saúde, agendamento do usuário pela Agentes Comunitárias de Saúde (ACS), obrigatoriedade de máscara para todos os usuários, descrição da paramentação e desparamentação correta e especifica para os profissionais de odontologia, auxiliares de saúde bucal e funcionários de serviços gerais, sala de espera com cadeiras distantes, ambiente aberto e ventilado, triagem prévia para todos os usuários, caso estes relatem ou apresentem sintomas de COVID-19 será notificado e orientado Quadro1. Os itens listados acima sofreram alterações e/ou não constavam no POP anterior.

Quadro 1 - Itens modificados no POP.

\begin{tabular}{|c|}
\hline Minimização de pacientes na sala de espera. \\
\hline Disposição das cadeiras com uma distância mínima de 1 metro. \\
\hline $\begin{array}{l}\text { Limitação dos pacientes que acompanham pacientes na sala de } \\
\text { espera. }\end{array}$ \\
\hline Uso de máscaras adequada dos pacientes, acompanhantes e equipe. \\
\hline $\begin{array}{l}\text { Fornecimento álcool } 70 \% \text { gel aos pacientes em todos os ambientes } \\
\text { da clínica. }\end{array}$ \\
\hline $\begin{array}{l}\text { Remoção dos objetos da sala de espera que possam } \\
\text { permitir infecção cruzada. }\end{array}$ \\
\hline $\begin{array}{l}\text { Ventilação do ambiente constante, preferencialmente } \\
\text { com janelas abertas. }\end{array}$ \\
\hline $\begin{array}{l}\text { Verificação de temperatura dos pacientes, previamente, } \\
\text { ao atendimento. }\end{array}$ \\
\hline $\begin{array}{l}\text { Exposição mínima de objetos, instrumentos e materiais na sala } \\
\text { do paciente, durante atendimento odontológico. }\end{array}$ \\
\hline Uso de barreiras físicas \\
\hline $\begin{array}{l}\text { Uso de equipamentos de proteção individual por todos os que } \\
\text { estejam na sala clínica. }\end{array}$ \\
\hline Evitar ou minimizar o uso de dispositivos geradores de aerossol. \\
\hline $\begin{array}{l}\text { Priorizar a utilização de instrumentos manuais } \\
\text { (evitar equipamentos ultrassônicos). }\end{array}$ \\
\hline $\begin{array}{l}\text { Esterilização de todos os instrumentos críticos, incluindo peças } \\
\text { de mão. }\end{array}$ \\
\hline Limpeza e desinfeção da sala clínica após cada atendimento. \\
\hline
\end{tabular}




\section{DISCUSSÃO}

O procedimento antigo já era bem construído, bem amplo, pois o perigo de contagio e infecção cruzada sempre existiram. A contaminação por HIV e hepatite sempre geraram preocupação. As maiores mudança inseridas foram o rigor com o cumprimento do Procedimento Operacional Padrão na Saude Bucal (POP) e as mudanças inseridas pelos requisitos para a prevenção do COVID-19.

As inovações tecnológicas produzidas pela inteligência humana, embora signifiquem avanços, podem gerar riscos à saude, quando não monitoradas de maneira adequada. Por isso, a qualidade do atendimento à população está relacionada a monitoração desse riscos. Por essa razão, a Agencia Nacional de Vigilância Sanitária (Anvisa) publica normas técnicas dedicadas aos serviços de saúde no intuito de levar aos profissionais da área instrumentais práticos para o gerenciamento dos riscos sanitários.

De acordo com a Anvisa, com a Nota técnica COVID-19 no 76/2020-SESAVCRO-ES-Conjunta, com o Protocolo de manejo clínico do COVID-19 as normas para o atendimento odontológico foram rigorosamente cumpridas e as mudanças foram implementadas. Quanto a organização dos atendimentos, passaram a ser feito o agendamento das consultas pelas agentes comunitárias de saude (ACS) ,programar os atendimentos com horários espaçados, priorizando idosos, hipertensos, diabéticos e gestantes, em procedimentos inadiáveis, agendamento dos procedimentos que geram aerossol como ultima consulta, depois de cada atendimento seguir com limpeza e desinfecção completa do ambiente e materiais, não deixar para o dia seguinte.

As medidas de prevenção mais preconizadas pelas organizações mundiais e sistemas de saude estão a lavagem frequente das mãos, ao uso dos EPls pela equipe de saúde bucal, deve ser completo para todos os profissionais de saúde bucal no ambiente clínico, deve-se evitar circular paramentado em outros ambientes e o distanciamento entre as pessoas descritas foram implementadas ou reforçadas no desenvolvimento do novo POP. ${ }^{[13,14]}$

Os protocolos de biossegurança não devem ser negligenciados, a limpeza e esterilização dos instrumentais, materiais, da sala clínica deve ser feita após cada atendimento, não deixar para o dia seguinte. Os atendimentos realizados sempre de forma a gerar a menor formação de aerossóis. ${ }^{[15]}$
A implementação de uma nova ferramenta de vigilância sanitária, o e-SUS VE, no qual situou um módulo especifico para registrar as notificações de COVID-19, o que poderia contribuir para o monitoramento da dispersão dessa doença. ${ }^{[2-6,16]}$

\section{CONCLUSÃO}

Algumas melhorias foram notadas como o respeito pelas recomendações dadas, melhora na pratica dos hábitos de higiene, maior cuidado com a própria saude, maior segurança percebida pelos pacientes, profissionais e equipe, diminuição da aglomeração na sala de espera. [17-19]

A pradonização da assistência pode resultar em benefícios para o usuário e para a equipe de saúde, possibilitando maior segurança as reais necessidades dos usuários.

O estabelecimento de protocolos facilita o entendimento da equipe, a cobrança dos supervisores e a percepção de saude. ${ }^{[20]}$ 


\section{REFERÊNCIAS}

1. Guimarães JJ. Biossegurança e controle de infecção cruzada em consultórios odontológicos. São Paulo: Santos, 2001. $536 \mathrm{p}$.

2. Ministério da Saúde. Secretaria ele Atenção Primária à Saúde - Protocolo de Manejo Clínico do COVID-19 na Atenção Primária à Saúde (Versão 5). Brasília-DF, março 2020.

3. Ministério da Saúde (BR). Secretaria de Vigilância em Saúde. Guia de Vigilância epidemiológica: emergência de saúde pública de importância nacional pela doença pelo coronavírus 2019 [internet]. Brasília: Ministério da Saúde;2020 [citado 2020 jul15]. Disponível em: https://portaldeboapraticas.iff.fiocruz.br/biblioteca/ guia-de-vigilancia-epidemiologica-emergencia-de-saude-publica-deimportancia-nacional/

4. Ministério da Saúde (BR). Agência Nacional de Vigilância Sanitária (Anvisa).anvisa.gov.br. Serviços Odontológicos: Prevenção e Controle de Riscos. Brasília, 2006.

5. Ministério da Saúde. Nota técnica n 9/2020 COVID-9 e atendimento odontológico no SUS. Disponível em: https:// Atendimento Odontológico no SUS. Acesso em: 24 jul. 2020.

6. Ministério da Saúde. Nota técnica n 16/2020 COVID-19 e Atendimento Odontológico no SUS. Disponível em: Nota Técnicas No 16/2020-CGSB/DSF/SAPS/MS. Acesso em: 24 jul.2020.

7. Izzetti R, Nisi M, Gabriele M, Graziani F. COVID-19 Transmission in Dental Practice: Brief Review of Preventive Measures in Italy. J Dent Res. 2020 Aug;99(9):1030-1038. http://dx.doi. org/10.1177/0022034520920580

8. Meng L, Hua F, Bian Z. Coronavirus Disease 2019 (COVID-19): Emerging and Future Challenges for Dental and Oral Medicine. J Dent Res. 2020 May;99(5):481-487. http://dx.doi. org/10.1177/0022034520914246.

9. Peng X, Xu X, Li Y, Cheng L, Zhou X, Ren B. Transmission routes of 2019-nCoV and controls in dental practice. Int J Oral Sci. 2020 Mar 3;12(1):9. http://dx.doi.org/10.1038/s41368-020-0075-9

10. Moraes DC, Galvão DCDF, Ribeiro NCR, DE Oliveira LSS, Azoubel MCF, Tunes UR. Atendimento Odontológico em tempos de COVID-19: compartilhando boas práticas protetivas e de biossegurança. BJMHH. 2020. 